\title{
1. Introduction - Social justice in the workplace: New challenges, new perspectives
}

Many today question the meaning of work, but few dare to consider it from an ethical standpoint. What is ethics? A desire to give meaning to one's activities based on one or more frames of justice. In the workplace, ethical reflection is both wished for and despised, welcomed and rejected. We sense its importance but are wary of the naivety behind it, or even its outright instrumentalisation. In practice, ethical reasoning is still caught between two seemingly dominant action logics: on the one hand, an economic logic, according to which problems could be solved by improving efficiency via a potentially very complex cost-benefit calculation; on the other hand, a political logic that underlines the importance of power relationships between employers and employees, the role of political strategies between the actors in an organisation, and the forms of government within that organisation.

These two logics are not equivalent: the political dimension of social life requires the most attention, as it raises the issue of the democratic regulation of the economy. But neither of them is adequate to address ethical issues and the challenges they raise for all of us, particularly in the professional sphere. This is compounded by a further difficulty: in practice, ethics is often confused with deontology, which refers to a set of obligations specific to a sector or a profession, but which is no substitute for an analysis of the meaning of action. Deontology serves merely as a guide to action: it is a condition, not a synonym, of ethics.

Thus, the idea that workers could express not only a desire for meaning, but also a desire for justice - or an 'ideal of good life', which, according to Aristotle, is the true definition of ethics - is ignored. Likewise, the idea that they could be considered as ethical subjects in their own right seems trivial compared with the dominant role played by calculation or power. Thus, we have reached an impasse: the question of meaning has never seemed so important, and it has never been so difficult to frame the debate in ethical terms. We are asking employees to 'give meaning' to an activity without recognising them as subjects capable of combining this endeavour with a simultaneous focus on justice. We may as well try to fill a leaking bucket. 
After many years of teaching and research, and having been involved in the development of a unique learning tool, ${ }^{1}$ I have come to the conclusion that this entire rationale must be rebuilt from scratch. I would argue that, while the question of the meaning of work is an inextricable part of the discussion on justice in the workplace, this discussion has changed completely since our societies entered a multicultural era marked by the diversity of values and the lack of a transcendental foundation to reason - in other words, an era of deep secularisation. ${ }^{2}$ This theory is based on three premises:

1. It is quite simply wrong to think that the world of work is cold and icy with no moral code, and that the role of ethics is to attribute morality to actions that have none. This rhetoric, which is found in some parts of the elite and in many managerial environments, ignores the fundamental reality of work. But it also ignores the society that we have been living in for several decades: since the end of the Cold War and the acceleration of trade, values have spread, convictions have been formed and unformed, and we have experienced a diversity of cultural references through our social lives - a situation which has had a retroactive effect on work. In the professional sphere, workers of all stripes - including the lowest skilled - are guided by values. But none of these values are preponderant. This has an important consequence: in practice, values conflict with each other. And these conflicts occur not just within social groups, but also within individuals. We are often torn between values of equal importance, which distort the way we think and make decisions. In the workplace, the baseline of ethical life is not a lack of values, but a conflict of values - which the scientific literature generally refers to as an 'ethical dilemma'. Thus, this first premise suggests that social ethics is based essentially on conflict, and that prioritising a set of dilemmas is one of the biggest challenges that people face in the workplace.

2. Value conflicts are not damaging in themselves. In open societies, they are largely inevitable and rather reassuring: they reflect the vibrancy of discussion and the strength of different opinions. The main question is, how can they be overcome? Here's the rub: in many organisations, these conflicts are swept under the carpet and, because they are not addressed, they result in brutality (the strong have dominion over the weak) or cynicism (values are vaunted and then, in practice, ignored). Thus, what initially looked like cultural openness or moral pluralism turns out to make no sense at all. This profound contradiction causes frustration, resentment and pain. But this situation also highlights an essential point: it is not harmony or uniformity that is missing, but the opportunity to overcome these conflicts using frames of justice. To put it differently, according to this second premise, it is not the value conflicts that cause a problem, but 
the fact that the actors do not have the normative supports they need to surmount them without renouncing their deep-rooted motivation for fairer working practices.

3. Last but not least, these frames of justice are plural. It is important to focus briefly on what this plurality means: it is not just the 'irreducible plurality of values' that, according to John Rawls, is found in open and secular societies. In this case, we are talking about a different kind of plurality, of the frames of justice themselves. In this book, I look at four such frames of justice: the ethics of discussion, the ethics of compromise, the ethics of development, and the ethics of recognition. Each is important, but their plurality is even more so. This has clear implications: in practice, there are several paths to overcome value conflicts within organisations, by focusing on achieving social justice. These paths vary according to different criteria, for example the nature of the problems encountered, the type of work organisation, the professional sector, or the institutional framework. They vary according to the context in which the dilemmas arise. Therefore, under this premise, it is the plural and contextual nature of the frames of justice that matters.

Everything starts with the conflict and ends with the context. That, in a nutshell, is the theory behind the approach proposed in this book - which, as we will see, will lead to a methodology. Nevertheless, this approach calls for a number of remarks to be made, which are essential to what follows.

1. The observations made above form the premises of a general rationale. These premises by no means imply that all situations of injustice can be reduced to intractable value conflicts, or that the methodology I am going to propose could serve as a universal 'law'. In the workplace, there are many injustices that are not related - or not only related - to value conflicts, for example redistributive inequality and the various forms of labour exploitation that are part and parcel of the development of global value chains. Moreover, a methodology is the opposite to a law: where the latter is designed to authorise or restrict, the former serves as a point of reference, a tool for navigating the twists and turns in the path ahead.

2. The term 'path' is crucial. The rationale regarding social injustice is binary in general: it either exists or it does not. Not only does this rationale ignore the dynamic and, in truth, historical nature of injustice, but it implies that injustice exists independently of the men and women who experience it, as if the path they had to travel played no role in the pursuit of fairer working practices. This is not unlike the welfare state, which redistributed income and created collective rights based on a standardised assessment of social risks: its strength (the ability to come to grips with social issues) was not 
infallible (there was no critical reflection on the need to change lifestyles and social relationships themselves). Thus, the path - or rather paths that I will discuss in this book entail more than just movement: they also suggest a relational transformation. They imply a changed relationship with oneself and with others; a change in social relationships. There are two reasons for this: these relationships are the primary cause of injustice; they determine its 'reproduction'. To put an end to them, individuals and groups must engage in a transformation, that is, they must extricate themselves from these relationships and demand that others be established instead. Clearly, however, this process is never really complete: a human life without relationships makes no sense at all. This is what the term 'path' refers to: bringing about a shift in relationships with a view to changing them, rather than ending them altogether. Following on from several authors, this term indicates a relational conception of social justice in organisations. ${ }^{3}$

3. Capitalism is not just an economic regime that combines wealth generation with growing inequality - probably the only regime in which the scale of these two extremes reaches such huge proportions. It is also a way of organising human activity, in which brutality and cynicism are likely to take radical forms. Clearly, capitalism does not relate only to the socio-economic sphere: it also designates a cultural form, in which the desire for immediate gain resembles a collective norm, with everything that implies. That said, we have known since Max Weber that profound changes were required within European societies to create a legitimate foundation for capitalism. We also know that interest-driven choices will not, by themselves, gain the support of their intended audience: in practice, a set of values is required to justify them and to ensure stakeholder engagement. ${ }^{4}$ Therefore, interpreting capitalism exclusively in terms of a cost-benefit calculation is not enough to change the existing situation: such a perspective is merely the veneer on top of what could be described as a deep 'reservoir of values' which leaders intend to control. Conversely, a transformative perspective is all about restoring the independence of these values, viewing value conflicts as the wellspring of social relationships, and making sure that workers have the frames of justice needed to surmount these conflicts.

4. Seeking alternatives to capitalism is a crucial battle for all human civilisations. However, once formulated, this observation calls for several clarifications:

- what Etienne Balibar quite rightly referred to as 'absolute capitalism' (i.e., the unparalleled dominion of this economic regime over every aspect of societal life), is coupled with huge internal pliability. ${ }^{5}$ In fact, 'capitalism' as a singular entity does not exist: not only 
are there several forms of capitalism, but it operates by creating and incorporating a multitude of diverse situations in different parts of the world, and within a wide variety of institutional frameworks. This situation goes hand in hand with highly evolving types of work organisation. Why? As Joseph Schumpeter showed, one of the driving forces of accumulation in competitive environments is innovation, which requires constant changes in the way added value is generated. So, although capitalism is deeply embedded in society, it is also a deeply unstable system, with constant tension between innovation and rationalisation, creativity and dominance. In terms of our subject here, this instability has decisive implications: it does not only mean that 'actors have room to manoeuvre', as sociologists used to say, but that the capitalist regime is beset by failings and flaws. Its grip on society is proportionate to these inherent issues;

- this observation is all the more important because many situations are not directly connected with this economic regime. It may seem incongruous to point this out, but there is more to the world of work than its objectification by the capitalist system: power relationships exist in all work environments, from public, semi-public and membership organisations, to the education, healthcare, humanitarian, cultural and social inclusion sectors, schools, churches, parties, unions, and so on. They are often concealed by what Henry Mintzberg called the organisation's 'mission' or indeed 'ideology'. ${ }^{6}$ Past experience even shows that numerous value conflicts occur in such environments, but that they are silenced - not by money considerations, but by an illusory homogeneous identity. Careful attention must be paid to this, at least if one is claiming, as I am, to offer workers in all organisations a way of surmounting these conflicts;

- changes in the structure of our economy are more necessary than ever. However, sociology has also taught us to be wary of an overly 'mechanistic' approach to social change, whereby modifying one structural variable would be enough to bring about a change in behaviours and also in social interactions. In fact, theories on social change have taught us to avoid two pitfalls: envisaging either unrestrained interactions, or interactions that are fully dependent on social structures. In the first case, the actors' freedom of choice is overestimated; in the second, too much importance is placed on structural determinisms. There is a series of 'mediations' between the two, consisting of tensions and ambivalence. This is all the more true in the present case because the advent of 
wage-earning work was accompanied not only by social rights, but also by forms of collective action that restrict the arbitrary power of employers and enable further changes. The growing precarity of the employer-employee relationship due to the constraints of financialised and algorithmic capitalism certainly calls for global responses, but it should not eliminate the scope for action at the organisational level. Clearly, the world of work is a tangled web of contrasting situations, but levers do exist to address the dilemmas that many workers face. Some are within reach, while others are much further off. The worst outcome would be if the desire to radically change the system became an antechamber to nostalgia and inaction.

5. That is why, in this book, I will situate my reflections at the organisational level. Of course, this concept itself has changed significantly in recent decades, giving rise to countless literature in the fields of psychology, sociology and management. Philosophy itself has joined their ranks, for better or for worse. But the most important thing is that the very meaning of 'organisation' seems to have changed completely in a matter of decades. The term 'organisation' has been recast to encompass networks, nexus of contracts, subcontracting chains, despatialisation and the acceleration of paces, polymorphous, flexible and agile businesses - but it has not disappeared. It has not lost its relevance on the ground - far from it. This is one of the most salient features of our time: while 'capitalism' is both everywhere and nowhere to be found in its original features, and while numerous work situations exist outside it and many action levers are available, the organisational level is essential to update these questions and provide real answers to them. By organisation, I do not just mean a production activity defined by the rules of law and economics, the same chain of command or a common goal: the term also reflects specific choices in the production process, the reporting structure, the management style, the people management policy, and professional identities. Therefore, this must be our starting point if we are to understand the actors' situation and support them along the path they have chosen to address it. ${ }^{7}$ More than ever, a relational approach to injustice means adopting an understanding outlook and being sensitive to the experience of workers on the ground.

This book was designed as a large-scale survey to provide a better understanding of the role that value conflicts ('ethical dilemmas') play in organisations, the cardinal forms of injustice that underlie them or result from them, the frames of justice that can overcome them, and the political implications of such a process. It looks closely at the work of certain authors, offers a didactic presentation of the frames of justice available to us, develops a general meth- 
odology for social actors, and puts this methodology to the test in several case studies. I will present the various stages of this methodology in a moment. Before that, I suggest we take a small philosophical excursus.

\section{Ethics is an arduous path \\ Baruch Spinoza}

When Spinoza's Ethics was published in 1677, it immediately drew strong criticism, similar to that previously faced by the author himself. For the religious and political authorities at the time, it raised a daunting prospect. In his book, Spinoza traces a path towards beatitude, with the same diligence and the same rigour as one would apply to drawing a geometric shape - but in defiance of the established authorities. Essences, scholia, correlates, attributes: the aim is to enable everyone to find their way in the world, and to find peace through reasoning alone. His method is completely different to those of Descartes, who saw reasoning as a basis for knowledge, a means of attaining truth and gaining mastery over nature. According to Spinoza, ethics is a means of achieving joy and beatitude. Its ultimate purpose is to enable human beings to break free of anything that demeans them, particularly feelings of sadness. It is based on propositions and axioms; it ebbs and flows, and starts over again towards its ultimate goal. It is an arduous path, a moving geometry. Spinoza contends that the rigour of reasoning is the bedrock of a moral life, and essential to give meaning to human life at both the individual and collective levels. In so doing, he attacks the very core of power, since the authorities at the time claimed to be the only source of liberating knowledge. Breaking free, and working methodically and tirelessly to achieve beatitude: that, in a nutshell, is the very essence of Spinozism.

In quoting Spinoza, this book has no intention of returning to the world as it was before labour, capitalism, Fordism or post-Fordism, to a world before the service economy, the financialisation of capitalism or the digital revolution. It seeks not to return to Spinoza's world, but to underscore the topicality of his work. However, it can only do this by accepting the legacy that separates us from him, starting with that of Smith, Marx and Weber, but also - more recently - that of sociology and management in all their diversity. Yet, this legacy does not prevent us from regarding ethics as a method. On the contrary, Spinoza's work is so topical because his view on these issues was so luminous and premonitory. This is especially true in today's world, where human beings have become cogs in the economic regime which they themselves invented, and which seems to be slipping increasingly out of their control.

The gist of my proposal is to take seriously the conflicts inherent in ethical life or, to be more precise, to use value conflicts as the starting point of ethical experience in contemporary times. This represents a profound break from 
the idea that ethics is no more than a catalogue of virtues, or derives merely from a set of procedures to better distribute resources or skills. None of these approaches provides a clear account of the value conflicts experienced by workers during the course of their activities; more seriously still, neither do they provide an adequate means of overcoming them. On this basis, I will gradually formulate a methodology, exploring its mechanisms, its underlying principles, and its different stages. Given the structure of power relationships in the world of work, an ethics such as this is always incomplete. However, this does not mean it is useless: my extensive experience in teaching, particularly with adults, has shown me that workers have growing needs in this respect. At the same time, such an ethics is incompatible with a schizophrenic approach that would segment problems or areas of action. Ethics does not just designate a 'sequence' in the development of individuals and organisations. It is the purpose of that development; the very source of meaning. Of course, in this book, Spinoza's view on beatitude has given way to a desire for justice and, in particular, to a relational approach to justice. But the process is exactly the same. In organisations, ethics does not take second place to politics: on the contrary, it finalises the power relationships and the choices made collectively. What is a democratic policy, in both the public and professional spheres? The ability to lend effectiveness to the frames of justice deemed to overcome value conflicts, with a view to creating a fairer world. It is time now to present the general outline of the book, and the various stages that go with it.

\section{OUTLINE OF THE BOOK}

The second chapter (Chap. 2 - The Spirit of the Enlightenment) revisits three approaches to social injustice and examines the connections they make with work: the economic approach to inequality, transformative political ecology, and the analysis of value conflicts ('ethical dilemmas') in the professional sphere. The first approach highlights the extent to which inequality has grown in contemporary times, and also how closely it is connected with the way in which work is valued or devalued. As Thomas Piketty points out, following the seminal work of Anthony Atkinson on inequalities, it is impossible to dissociate inequality from what goes on in the productive sphere. Nevertheless, it is on this that the debate must focus. What does 'reinstating the value of work' involve? Addressing the glaring imbalances in wealth distribution? Certainly. It is nonetheless striking that, for most economists of inequality, the implicit form of this reinstatement is 'merit', which is another word for 'work ethics'. Are they suggesting that we should fight inequality from the confines of a simplistic philosophy on social recognition, namely that of individual merit? In view of this, it is understandable that political ecologists seek to ignore work, which is regarded as being too tainted by productivism, 
and to underline the urgency of an entirely new kind of ethics that strengthens the links between human beings and the biosphere and reinstates a care-based society. However, despite its crucial importance, this approach does not explain how to achieve such a society. Likewise, it fails to answer the question as to what the sources of ethical life in today's society are, especially in the workplace. There is nothing new about this debate: it was already going on during the Enlightenment period, and was central to the controversy between Voltaire and Rousseau. One sought to track down absolutisms and brandish a universally valid ethics of the future, whereas the other was interested in present-day life and the ethical consistency of social relationships. While my work does not ignore Voltaire, it is inspired by Rousseau's view of his own society. Therefore, the third approach, which is the one I will adopt, consists in focusing on the world of work and highlighting the importance of ongoing value conflicts in the sphere of production. Work does not just lie 'somewhere' between merit and exploitation. It is also the setting of a cultural experience. And this experience is built on conflict: it is the experience of a rift between opposing values. ${ }^{8}$ My proposition? Workers are not suffering from a lack of harmony or uniformity, but from a lack of frames of justice to overcome these conflicts. Thus, a better understanding of the historical link between work and values is needed, and I will discuss this in the following chapter.

The third chapter (Chap. 3 - Work and Values: A Critical Genealogy) will further explore the relationship between work and values by looking closely at the writings of two founding fathers: Adam Smith and Karl Marx. As we will see, neither Smith's nor Marx's analysis is as simple as the caricatures would have us believe. Adam Smith, first of all. The author of the Theory of Moral Sentiments and Wealth of Nations, who was a philosopher before becoming an economist, set up a theory in which he began by distrusting wealth - which he described as a 'seductive illusion' - and ended by wholeheartedly supporting it, arguing that 'growth in national wealth' is the ultimate objective of all social relationships. In this latter perspective, workers are regarded as abstract beings; cogs in a huge industrial machine that is beyond their control. Initially conceived as an ethical compass that guides ordinary relationships, 'sympathy' cannot cross the threshold into the pin factory. No more 'sympathy' between employers and employees, and between workers themselves, but compliance with rules and productivity gains for the sake of collective prosperity. A situation that is, in fact, untenable. A certain kind of ethics must therefore be reinstated, namely that of individual merit, which may be accompanied by numerous value judgements, provided that they never tarnish the new perspective taking shape: that of an ethics that continues to play a functional role in increasing national wealth. The idea that workers may have values that differ from - and indeed clash with - those of the organisation becomes literally inconceivable. In the professional sphere, ethics develop within a relationship 
of functional dependence on wealth. Thus, it becomes unilateral: there is almost no margin of manoeuvre to discuss the meaning of work in a world driven that way.

Marx's response would not be long in coming. The author of the Manuscripts of 1844 and Das Kapital would continually contest the very foundations of this approach. With him, a completely new perspective takes shape: as we know, Marx was a fierce critic of 'bourgeois morality', of values brandished like trophies to conceal the brutality of social relationships in capitalist regimes. Yet, as Steven Lukes shows, his work contains the foundations of a social ethics which Lukes describes as a 'morality of emancipation', and which consists in seeking emancipation from the law rather than within the law. This objective has an essentially conflictual basis: it makes sense only in the context of class conflict, of which it is the ethical expression. Thus, exploitation is theorised as being the typical form of social injustice. It is in the light of exploitation that social conflict is redefined, that political revolution is anticipated, and that the subject of history is identified. The strengths and weaknesses of this approach are quite clear: as a radical form of behaviour, which is supposed to reflect the most fundamental characteristics of capitalism, exploitation is established as the only - indeed systematic - expression of all social injustices. This does not mean, however, that Marx is insensitive to singular experiences, particularly those of women and children: numerous passages in his writings bear witness to his sensitivity in this respect. But, in his view, work cannot be considered as an ethical experience, in which workers call upon one or more frames of justice to fight against the specific indignity they face. For him, this matter is settled, as it were, by the general picture he draws of capitalist society: all that counts is overthrowing the socio-political and socio-legal structures that underpin it. Focused on highlighting the anthropological radicality of work in modernity, Marx also came up with a unilateral conception of social ethics - although the route he took was very different to that of his Scottish predecessor.

Everything changes, however, if one considers that values give rise to recurring conflicts. In other words, if one accepts the Weberian theory of 'value polytheism' - which describes the diversity of convictions in advanced modernity - bearing in mind that values are not set in stone and, above all, that they conflict with each other in all areas of social life, including work. These conflicts occur not only between classes or social groups, but also between individuals themselves. From an axiological perspective, the workplace is a scene of discord. To achieve social justice within organisations, this discord must not be erased but addressed, thereby enabling those affected to overcome it by use of frames of justice. This book posits a dual hypothesis in this regard: (i) the problem is not so much the existence of value conflicts: in an open and multicultural society, such conflicts are not surprising. It is more the fact that the actors do not have a frame of justice that allows them to overcome these 
conflicts without renouncing their deeply held values. They are therefore faced with a choice of either brutality or cynicism, which can be very damaging to them. This impasse may even be regarded as a form of organisational or institutional violence; (ii) these frames of justice are plural. This pluralism is not simply a pluralism of values, but a pluralism of the normative supports themselves, an epistemological pluralism. Rather than proposing a one-size-fits-all method, scientific research should seek to understand the needs of actors in specific contexts. The following chapter discusses this pluralism of values.

In this fourth chapter (Chap. 4 - Social Justice in the Workplace: Four Frames of Justice to Overcome Ethical Dilemmas), the book suggests four frames of justice, which are themselves intended as normative supports to help male and female workers overcome the value conflicts they may encounter in their day-to-day activity. The idea of 'support' is important: it implies that the frames of justice I am talking about may act as reference points, rather than binding frameworks. Therefore, discussing these frames of justice means underlining their potential effect on social life. They, too, are not set in stone: they do not confirm the intangible superiority of a value or set of values, but neither do they accept relativism - the idea that all values are equal. Having their own logic, they can be used to address value conflicts, describe a cardinal form of injustice, formulate a normative ideal, and build a path from one to the other. The four frames I will explore here are the following: ethics of discussion (Jürgen Habermas, Nancy Fraser), ethics of compromise (Laurent Thévenot and Luc Boltanski, Yves Clot), ethics of development (Amartya Sen, Martha Nussbaum) and ethics of recognition (Axel Honneth, Christophe Dejours, Judith Butler). In as didactic a manner as possible, the book examines the most salient characteristics of each frame of justice, and looks at the attention they give to work itself. It attempts to demonstrate how each of them provides the elements of a common language, in other words a set of rules or criteria for identifying and overcoming ethical dilemmas in the workplace. The aim is to help the reader understand these different normative supports by showing how they are linked with his or her own professional situation. The chapter ends with a comparative overview of these supports, which will be 'tested' in several practical case studies in the following chapter.

The fifth chapter (Chap. 5 - Social Justice in the Workplace: Three Recent Case Studies) relates several recent case studies to explore how this methodology can be used in and improved by different professional contexts. Co-authored with Marc Zune, the first case study addresses the 'platform capitalism' and shows how workers are subjected to a very harsh working environment. This situation can be interpreted in two ways. First, as an example of labour exploitation, in which added value is created not only by forcing workers to accept low wages, but also by using a permanently available and willingly unstable workforce that is paid by the job and has no social 
protection. Despite its relevance, this approach does not explain why workers make themselves so readily available. In this sector, the workers seem to be confronted with an underlying dilemma: how to obtain decent working conditions while maintaining their independence - or indeed their individualism - and remaining on the periphery of the wage-earning world. Unless they can surmount it, they will remain dependent on the main initiators of "platform capitalism'. Rather than evading this dilemma, the aim should be to face up to it - and to try and overcome it using several frames of justice. What are the practical implications of this? That is what the first case study will establish.

Co-authored with Pierre Stassart, Antoinette Dumont, Camille Lacombe and Stéphanie Klaedtke, a second case study underlines the challenges of the agroecological transition. There is one point worth noting: this is the first time that specialists in the agroecological transition have attempted to implement the methodology proposed here. The team has improved the initial version of the methodology by showing the important role played by the researcher-actor relationship in identifying and/or stabilising the frames of justice chosen by workers on the ground. In fact, after highlighting the importance of a transformative transition, this case study draws on several recent research works to shed light on the value conflicts encountered by the actors in the agroecological transition. This second case study looks at vegetable production in Wallonia from an agroecological perspective, at a French association of veterinarians and sheep breeders struggling to provide the tools needed for work practices that derogate from professional norms, and at an association of seed producers who want to get their practices recognised as legitimate under European phytosanitary regulations. In each instance, specific dilemmas occur, injustices are brought to light and pathways are suggested, which vary according to the contexts. Ethics of compromise for the vegetable growers, ethics of capabilities for the association of breeders and veterinarians, ethics of recognition for the seed producers. There is no single answer but a wide range of feasible approaches. How did these elements emerge? What do they lead to in practical terms? What lessons can be drawn from them for our own approach? That is what we will discover from this second case study, which includes three field surveys.

The third case study is based on a close dialogue with Florence Osty and pays tribute to French sociologist Marc Uhalde, who died prematurely. It looks at sociological consulting within organisations, and shows that consultants fluctuate constantly between expertise (characteristic of an auditor's posture) and listening (characteristic of an understanding, even clinical, posture). This case study reveals how consultants can use the ethics of compromise to deal with this dilemma, and how it requires them to clarify the ethical foundations of their action. However, they cannot use just one frame of justice as a reference. In practice, the choice of a frame of justice depends on the reality of 
each organisation, but also on the relationship between the consultant and their clients. Above all, the outcome of this case study is that the consultants' task is not only to overcome their own dilemmas, but to ensure that the value conflicts of the actors with whom they work can also be identified as such. Far from being just a catalogue of virtues, an ethics of consulting could consist in helping the members of an organisation to move away from a purely interest-driven approach, to understand the importance of value conflicts, and thus experience otherness. What does this mean for consultants and the organisations who call on them? That is what this third case study will establish. Finally, the chapter summarises the methodology tested on the ground, and formalises two research results: the importance of having a methodology composed of successive steps; the role played by certain factors in identifying the most context-appropriate frame of justice.

The sixth and final chapter (Chap. 6 - What Is a More Just Workplace? Prospects for the Future) will draw the conclusions of this process, focusing in particular on the political consequences of such reflection. It stresses the necessity of completing the usual exogenous critique with a more endogenous critique of our economic system. In other words, the critical focus cannot be placed only on the external limitations of the system, requiring new regulations worldwide to create a more socially and ecologically sustainable world; it must also identify - and work with - the tensions within it. As a result, politics takes on a new meaning: it's less of a project and more of a requirement, whereby the effectiveness of the frames of justice claimed by workers in specific contexts lies at the forefront of political awareness and struggles. In an effort to strengthen dialogue with trade unions, I will conclude by arguing that such an approach is also - perhaps even primarily - applicable to workers in the Global South.

\section{AIM OF THE BOOK}

All in all, this book is a call to renew social justice theories: the aim is to complement 'redistributive justice' with 'reconstructive justice', which will help social actors clarify the ethical basis of action rather than impose ex-nihilo a pre-defined - and often impossible to achieve - ethical code. More broadly speaking, the goal is to underline the contribution of work to reflections on the foundations of civility in our global societies and to recall the historicity of social justice theories, which must be continuously reviewed and improved work plays a central role in all these areas. 


\section{NOTES}

1. Ethical Dilemmas in Contemporary Organisations (EDICO) is a training scheme designed to help adults identify, discuss and surmount ethical dilemmas in their working environment. It has been financed and supported by the UCLouvain programme 'Digital University'. It's available as an Open Educational Resource (OER) on: https://oer.uclouvain.be/jspui/handle/20.500.12279/646

2. While this change is inherent to the process of secularisation and disenchantment that occurred when western societies entered modernity, it could be argued that the end of the Cold War marked the start of a new phase. This phase is characterised by two trends: an increase in cultural exchanges and a rise in social inequality in a 'globalised' world. From an economic perspective, these two trends go hand in hand with the emergence of a new regime of accumulation (financialised and algorithmic capitalism), and with the shift to a service economy.

3. On this subject, see: Mora Cortes, Andres Felipe (2017). Politique sociale et transformation sociale. Justice et mouvements sociaux dans le domaine de l'enseignement supérieur en Colombie (1998-2014), Louvain-la-Neuve: PUL. The author advocates a 'relational approach to injustice and social exclusion'. For an earlier basis, see: Bajoit, Guy (1992). Pour une sociologie relationnelle, Paris: PUF.

4. Boltanski, Luc and Thévenot, Laurent (2006). On Justification. The Economies of Worth, Princeton: Princeton University Press.

5. Balibar, Etienne (2017). 'From Historical to Absolute Capitalism? Towards a New Critique of Political Economy', Conference at the French Institute of Budapest, 22 March. See also: Hall, Peter A. and Soskice, David (2001). Varieties of Capitalism: The Institutional Foundations of Comparative Advantage, Oxford: Oxford University Press.

6. Mintzberg, Henry (1983). Power In and Around Organisations, The University of Michigan: Prentice Hall.

7. On this issue, see international investigations led by the Interuniversity Research Centre on Globalization and Work (CRIMT) in Montreal: http://www.crimt.org/ EN_Index.html. See also: Willmott, Hugh, and Alvesson, Mats (2012). Making Sense of Management. A Critical Introduction, London: Sage; Pichault, François (2013). Change Management. Towards Polyphony, Brussels: De Boeck; Laloux, Frédéric (2014). Reinventing Organisations, Brussels: Nelson Parker; Huault, Isabelle, Taskin, Laurent, Grey, Christopher and Perret, Véronique (2016) (eds). Critical Management Studies: Global Voices, Local Accents, London: Routledge.

8. Sainsaulieu, Renaud. (2014). L'identité au travail. Les effets culturels de l'organisation, Paris: Presses de Sciences Po [1977]. 